\title{
Anthropometric factors and breast cancer risk among urban and rural women in South India: a multicentric case-control study
}

\author{
A Mathew ${ }^{*, 1}$, V Gajalakshmi ${ }^{2}$, B Rajan', V Kanimozhi ${ }^{3}$, P Brennan ${ }^{4}$, BS Mathew' and P Boffetta ${ }^{4}$ \\ 'Regional Cancer Center, Trivandrum, India; ${ }^{2}$ Epidemiologic Research Center, Chennai, India; ${ }^{3}$ Rai Memorial Hospital, Chennai, India; ${ }^{4}$ International \\ Agency for Research on Cancer, Lyon, France
}

\begin{abstract}
Breast cancer (BC) incidence in India is approximately twice as high in urban women than in rural women, among whom we investigated the role of anthropometric factors and body size. The study was conducted at the Regional Cancer Centre, Trivandrum, and in three cancer hospitals in Chennai during 2002-2005. Histologically confirmed cases $(n=1866)$ and age-matched controls $(n=1873)$ were selected. Anthropometric factors were measured in standard ways. Information on body size at different periods of life was obtained using pictograms. Odds ratios $(\mathrm{OR})$ of $\mathrm{BC}$ were estimated through logistic regression modelling. Proportion of women with body mass index $(\mathrm{BMI})>25.0 \mathrm{~kg} / \mathrm{m}^{2}$, waist size $>85 \mathrm{~cm}$ and hip size $>100 \mathrm{~cm}$ was significantly higher among urban than rural women. Risk was increased for waist size $>85 \mathrm{~cm}$ (pre-menopausal: $\mathrm{OR}=1.24,95 \% \mathrm{Cl}$ : 0.96-1.62; post-menopausal: I.6I, $95 \% \mathrm{Cl}$ : I.22-2.12) and hip size $>100 \mathrm{~cm}$ (pre-menopausal: $\mathrm{OR}=1.47,95 \% \mathrm{Cl}$ : $1.05-2.06$; post-menopausal 2.42, $95 \%$ $\mathrm{Cl}: 1.72-3.4 \mathrm{I})$. Large body size at age $10(\mathrm{OR}=1.75,95 \% \mathrm{Cl}: \mathrm{I} .0 \mathrm{I}-3.03)$ and increased $\mathrm{BMI}(\mathrm{OR}=1.33,95 \% \mathrm{Cl}: 1.05-1.69$ for $25.0-29.9 \mathrm{~kg} / \mathrm{m}^{2}$ and $\mathrm{OR}=1.56,95 \% \mathrm{Cl}: 1.03-2.35$ for $\left.30+\mathrm{kg} / \mathrm{m}^{2}\right)$ were associated with pre-menopausal BC risk. Our data support the hypotheses that increased anthropometric factors are risk factors of BC in India.

British Journal of Cancer (2008) 99, 207-213. doi:10.1038/sj.bjc.6604423 www.bjcancer.com
\end{abstract}

Published online 10 June 2008

(c) 2008 Cancer Research UK

Keywords: breast cancer risk; anthropometric factors; urban-rural

Breast cancer $(\mathrm{BC})$ is the most common malignancy in women worldwide, with generally higher incidence rates in urban populations (Parkin et al, 2002). In India, the incidence is approximately twice as high among urban than rural women, ranging from 25 to 30 per 100000 women (NCRP, 2006). Cancer registry data from the rural regions of Barshi in western India (NCRP, 2006), Karunagappally and Thiruvananthapuram - the latter two in the more developed South India - have consistently shown lower incidence than in urban registries (ranging from 7 to 20 per 100000 females) (reports from cancer registries).

Most large studies have found that women who are overweight or obese, especially those who gain weight throughout adulthood, are at an increased risk of BC after menopause (Friedenreich, 2002; Vainio and Bianchini, 2002; Carmichael and Bates, 2004). Conversely, in most but not all case-control and cohort studies, an inverse relationship has been found between weight and BC among pre-menopausal women (Friedenreich, 2002; Carmichael and Bates, 2004). Risk increases with increasing height (Friedenreich, 2002), whereas a positive association with waist circumference or waist-to-hip ratio (WHR) has been reported in both pre- and post-menopausal women (Connolly et al, 2002).

Increased body mass index (BMI) and WHR are increasingly a concern in many low-resource countries, and particularly in urban India. Two large cross-sectional studies in North India have reported that increased BMI is more common in urban women

*Correspondence: Dr A Mathew; E-mail: amathew@rcctvm.org Revised 23 April 2008; accepted 25 April 2008; published online 10 June 2008 than in rural women (Chadha et al, 1997; Singh et al, 1997); this, along with other factors that vary according to residence (e.g., reproductive and other hormonal factors, diet and physical activity), may therefore contribute to the urban-rural $\mathrm{BC}$ differences.

The present study investigated the pattern of anthropometric factors among urban and rural women and their role in BC aetiology in India as well as their contribution to the urban-rural differences in $\mathrm{BC}$ rates.

\section{MATERIALS AND METHODS}

In 2002-2005, a case - control study was conducted at the Regional Cancer Centre (RCC), Trivandrum, Kerala, and in three cancer hospitals in Chennai, Tamil Nadu, India. The cases $(n=1866)$ were women with histologically confirmed incidence of primary BC who attended the study hospitals. The controls $(n=1873)$ were women without cancer who accompanied cancer patients (those accompanying BC patients were excluded), and who matched to cases by age ( \pm 5 years) and residence status (urban/rural). The institutional review boards of each participating centre approved the study. Written informed consent was obtained from all participants. Participation rates were more than $90 \%$ for both cases and controls.

In-person interview of each case and control was conducted by trained interviewers using a pre-tested structured questionnaire covering demographic and socioeconomic variables, reproductive history, time spent in household activities on a normal day, residential history, occupational history, personal and family 
medical history, tobacco and alcohol habits, and diet. Anthropometric measurements were taken at the end of the interview.

All subjects were asked to list all places of residence where they had lived for at least 1 year, starting with the place of birth. Urban/ rural residence status was collected according to the definition of national census. If the subject lived in a 'panchayat', residence status was defined as 'rural' and all other areas such as 'municipality' and 'corporation' as 'urban'. If the subject migrated to an urban area and lived there during the immediate previous 10 years, residential status was assigned as 'urban' and vice versa.

Socioeconomic status was assessed by summing the independent scores given to home ownership, number of rooms, number of people living in the house, availability of toilet and running water as well as possession of comfort/luxury items, such as electrical/gas stove, refrigerator, TV, air conditioner, car, motorcycle/scooter, bicycle and computer, owned by the subject.

Height (without shoes in $\mathrm{cm}$ ) and weight in light clothing (in $\mathrm{kg}$ ) of each subject were measured using standard equipment. Weight was measured with light clothing. Waist size (in $\mathrm{cm}$ ) was measured using a tape at the navel level around the skin, and hip size (in $\mathrm{cm}$ ) was measured with light clothing at the widest part. All measurements were done twice in succession and averaged for a final value. Body mass index $\left(\mathrm{kg} / \mathrm{m}^{2}\right)$ was grouped into three categories, namely lean weight $(\mathrm{BMI} \leqslant 25)$, overweight $(25<$ $\mathrm{BMI}<30)$ and obese $(\mathrm{BMI} \geqslant 30)(\mathrm{WHO}, 1998)$. Waist-to-hip ratio was computed by taking the ratio of waist size (in $\mathrm{cm}$ ) and hip size (in $\mathrm{cm}$ ) and grouped into two categories, namely $\leqslant 0.85$ and $>0.85$ (Royal College of Physicians Report, 1998). Furthermore, a total of nine different body sizes (pictogram) (Figure 1) were shown to each subject to indicate their body sizes at different periods of life (at 10 years, 20 years and the period when the data were collected).

\section{Data analysis}

The distribution of various anthropometric factors among urban and rural women in the control group was obtained and the differences were tested using the $\chi^{2}$ statistic (Fisher's exact test was used if the expected value of a cell was less than 5 (Armitage and Berry, 1994). The odds ratios (OR) of BC and their $95 \%$ confidence intervals (CI) for anthropometric factors and body size were estimated separately by menopausal status and residence status through unconditional logistic regression models adjusted for age at recruitment, centre, religion, marital status, education, socioeconomic status, residential status, age at first childbirth, menopausal status, parity, duration of breast feeding, level of physical activity and other factors (Breslow and Day, 1980). Multiplicative terms were added to the regression models to test for the interaction between anthropometric factors and physical activity. The ORs were modelled using a linear relationship between the anthropometric factors/body size and the log odds of disease. All analyses were performed using the statistical package SPSS.

\section{RESULTS}

There were 1866 cases (735 urban and 1131 rural women) and 1873 controls (631 urban and 1242 rural) in the study. Approximately $64 \%$ of urban cases were from Chennai, whereas $80 \%$ of rural cases were from Trivandrum; approximately $63 \%$ of urban controls were from Chennai and $79 \%$ of rural controls were from Trivandrum. Of cases, 21 and $24 \%$ of controls in Chennai moved from rural areas to live in urban areas during the past 10 years, whereas the corresponding figures in Trivandrum were 10 and $8 \%$. Migration from urban to rural areas, during the past 10 years and continued residence in rural areas was 9 and 7\%, respectively, for cases and controls in Trivandrum and only 3 and $2 \%$, respectively, in Chennai.

Socioeconomic status was significantly different among urban and rural women in Trivandrum (19 vs $11 \%$ in the highest quintile) and Chennai (33 vs $13 \%$ in the highest quintile). The proportion with higher education was higher among urban than rural women (15 vs $12 \%$ for education $>12$ years in Trivandrum and 6 vs $0.4 \%$ in Chennai). In Chennai, Christians and Muslims were more frequent in urban than in rural women (11 vs 6\% Christians and 7 vs $4 \%$ for Muslims), whereas urban-rural religious proportions were similar in Trivandrum.

The prevalence of obesity in urban women was 9 and $10 \%$, respectively, in Trivandrum and Chennai, whereas the corresponding figures among rural women were 3 and 5\%. Approximately 36 and $30 \%$ of women in Trivandrum and Chennai urban areas had waist size $>85 \mathrm{~cm}$, whereas the corresponding proportions in the rural population were 21 and $18 \%$. Similarly, the proportion of hip size $>100 \mathrm{~cm}$ was higher in urban than in rural women (16 vs 7\% in Trivandrum and 23 vs 14\% in Chennai). No difference according to WHR between the urban and rural populations was observed. Body size at 10 years of age was higher in the urban women in both Chennai and Trivandrum, whereas body size at age 20 and at the time of interview was higher in the urban women only in Chennai (Table 1).

Among pre-menopausal women, an increased BC risk was observed for $\mathrm{BMI}>25.0(\mathrm{OR}=1.33$ (95\% CI: $1.05-1.69)$ for BMI: $25.0-29.9$ and $\mathrm{OR}=1.56$ (95\% CI: $1.03-2.35)$ for $\mathrm{BMI} \geqslant 30)$, waist size $>85 \mathrm{~cm}(\mathrm{OR}=1.24,95 \%$ CI: $0.96-1.62)$, hip size $>100 \mathrm{~cm}$ $(\mathrm{OR}=1.47 ; 95 \% \mathrm{CI}: 1.05-2.06)$ and increased body size at 10 years of age $(O R=1.75 ; 95 \%$ CI: $1.01-3.03$ for figures $4-9$ of the pictogram). In the stratified analysis, the corresponding risks were slightly higher among pre-menopausal rural women, but none was significant among pre-menopausal urban women (Table 2).

Among post-menopausal women, an increased BC risk was observed for height $\geqslant 160 \mathrm{~cm}(\mathrm{OR}=1.61 ; 95 \% \mathrm{CI}: 1.08-2.42)$, waist size $>85 \mathrm{~cm}(\mathrm{OR}=1.61 ; 95 \% \mathrm{CI}: 1.22-2.12)$ and hip size $>100 \mathrm{~cm}(\mathrm{OR}=2.42 ; 95 \% \mathrm{CI}: 1.72-3.41)$, increased body size at 20 years $(\mathrm{OR}=1.23 ; 95 \% \mathrm{CI}: 0.90-1.70)$ and the body size at the time of interview $(\mathrm{OR}=1.29 ; 95 \% \mathrm{CI}$ : $0.92-1.90)$. In the stratified analysis, similar BC risks were observed among pre-menopausal urban and rural women (Table 2). None of the terms of interaction
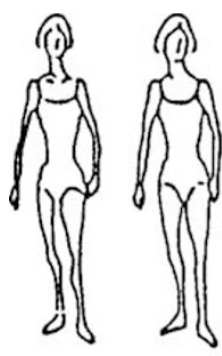

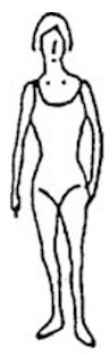

3

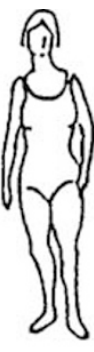

4

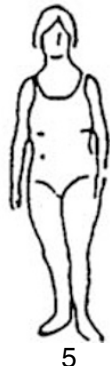

5

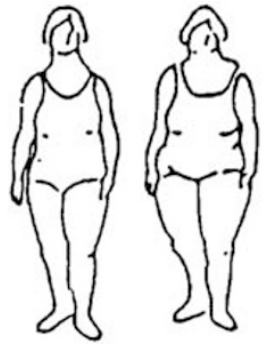

6

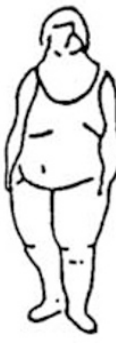

8

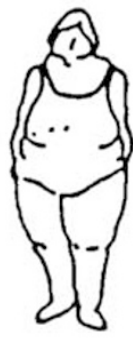

9

Figure I Body size. 
Table I Distribution of controls with respect to anthropometric factors and body size

\begin{tabular}{|c|c|c|c|c|c|c|c|c|c|c|}
\hline \multirow[b]{3}{*}{ Factors } & \multicolumn{4}{|c|}{ Trivandrum } & \multirow[b]{3}{*}{$P$-value } & \multicolumn{4}{|c|}{ Chennai } & \multirow[b]{3}{*}{$P$-value } \\
\hline & \multicolumn{2}{|c|}{ Urban $(n=233)$} & \multicolumn{2}{|c|}{ Rural $(n=975)$} & & \multicolumn{2}{|c|}{ Urban $(n=384)$} & \multicolumn{2}{|c|}{ Rural $(n=28 I)$} & \\
\hline & $\mathbf{N}$ & $\%$ & $\mathbf{N}$ & $\%$ & & $\mathbf{N}$ & $\%$ & $\mathbf{N}$ & $\%$ & \\
\hline \multicolumn{11}{|l|}{$\mathrm{BMI}\left(\mathrm{kg} / \mathrm{m}^{2}\right)$} \\
\hline$<25.0$ & 136 & 58.4 & 721 & 73.9 & 0.0001 & 229 & 57.5 & 209 & 78.3 & 0.00001 \\
\hline $25.0-29.9$ & 77 & 33.0 & 220 & 22.6 & & 118 & 29.6 & 38 & 14.2 & \\
\hline$\geqslant 30.0$ & 20 & 8.6 & 34 & 3.5 & & 40 & 10.1 & 13 & 4.9 & \\
\hline Unknown & & & & & & | | & 2.8 & 7 & 2.6 & \\
\hline \multicolumn{11}{|l|}{ Height (in cm) } \\
\hline$<160$ & 204 & 87.6 & 852 & 87.4 & 0.944 & 342 & 85.4 & 227 & 85.0 & 0.915 \\
\hline$\geqslant 160$ & 29 & 12.4 & 123 & 12.6 & & 45 & 11.3 & 33 & 12.7 & \\
\hline Unknown & & & & & & II & 2.8 & 7 & 2.6 & \\
\hline \multicolumn{11}{|l|}{ Waist size (in $\mathrm{cm}$ ) } \\
\hline$\leqslant 85$ & 150 & 64.4 & 772 & 79.2 & 0.0001 & 270 & 67.8 & 212 & 79.4 & 0.002 \\
\hline$>85$ & 83 & 35.6 & 203 & 20.8 & & 119 & 29.9 & 48 & 18.0 & \\
\hline Unknown & & & & & & 9 & 2.3 & 7 & 2.6 & \\
\hline \multicolumn{11}{|l|}{ Hip size (in cm) } \\
\hline$\leqslant 100$ & 197 & 84.5 & 902 & 92.5 & 0.0001 & 299 & 75.1 & 223 & 83.5 & 0.019 \\
\hline$>100$ & 36 & 15.5 & 73 & 7.5 & & 90 & 22.6 & 37 & 13.9 & \\
\hline Unknown & & & & & & 9 & 2.3 & 7 & 2.6 & \\
\hline \multicolumn{11}{|l|}{ WHR } \\
\hline$\leqslant 0.85$ & 53 & 22.7 & 260 & 26.7 & 0.22 & 150 & 37.7 & 103 & 38.6 & 0.657 \\
\hline$>0.85$ & 180 & 77.3 & 715 & 73.3 & & 248 & 62.3 & 157 & 58.8 & \\
\hline Unknown & & & & & & & & 7 & 2.6 & \\
\hline \multicolumn{11}{|l|}{ Body size at 10 years $^{\mathrm{a}}$} \\
\hline Figure I & 95 & 40.8 & 449 & 46.1 & 0.02 & 87 & 21.9 & 95 & 35.6 & 0.001 \\
\hline Figure 2 & 113 & 48.5 & 450 & 46.2 & & 248 & 62.3 & 146 & 54.7 & \\
\hline Figure 3 & 22 & 9.4 & 47 & 4.8 & & 50 & 12.6 & 20 & 7.5 & \\
\hline Figures 4-9 & 3 & 1.3 & 29 & 3.0 & & 13 & 3.3 & 6 & 2.2 & \\
\hline \multicolumn{11}{|l|}{ Body size at 20 years $^{\mathrm{a}}$} \\
\hline Figures I+2 & 87 & 37.3 & 362 & 37.1 & 0.79 & 84 & 21.1 & 89 & 33.3 & 0.001 \\
\hline Figure 3 & 112 & 48.1 & 486 & 49.8 & & 187 & 47.0 & 121 & 45.3 & \\
\hline Figures 4-9 Unknown & 34 & 14.6 & 127 & 13.0 & & 127 & 31.9 & 57 & 21.3 & \\
\hline \multicolumn{11}{|l|}{ Current body size $\mathrm{e}^{\mathrm{a}}$} \\
\hline Figures $1+2+3$ & 9 & 3.9 & 37 & 3.8 & 0.54 & 188 & 47.2 & 149 & 55.8 & 0.0001 \\
\hline Figures 4-9 & 224 & 96.1 & 938 & 96.2 & & 210 & 52.8 & 118 & 44.2 & \\
\hline
\end{tabular}

$\mathrm{BMI}=$ body mass index; $\mathrm{WHR}=$ waist-to-hip ratio. ${ }^{a}$ See Figure I (pitcogram).

between anthropometric factors and levels of physical activity was statistically significant (data not shown).

\section{DISCUSSION}

The present study is of the urban-rural differences in BC incidence centres on anthropometric factors and body size at different time periods of life and their relationship to BC risk. The proportion of women with augmented anthropometric factors and larger body size in their early years of life was higher among urban women, in accord with two cross-sectional studies in North India comprising several thousand individuals (Chadha et al, 1997; Singh et al, 1997). Although the present study was hospital-based in design, the BMI assessed among controls in urban and rural areas was in agreement with the above-mentioned studies in North India, indicating their representative nature for the population.

Several anthropometric factors were associated with BC risk in both pre- and post-menopausal women and in both urban and rural women. Although these factors appear to contribute to BC aetiology in India, they are unlikely to explain most of the urban- rural difference in $\mathrm{BC}$ rates in India. For example, assuming that the factors associated with increased OR are true and that the exposure in controls shown in Table 3 is representative, hip size $>100 \mathrm{~cm}$ would explain $12 \%$ of $\mathrm{BC}$ in urban and $9 \%$ in rural women or $9 \%$ and $11 \%$, respectively, for waist size $>85 \mathrm{~cm}$. On the other hand, greater opportunities for diagnosis in urban areas may contribute to some extent.

Few studies have investigated anthropometric factors and $\mathrm{BC}$ risk in India. Our findings of increases associated with augmented anthropometric factors in post-menopausal women accord with previous results (Friedenreich, 2002; Vainio and Bianchini, 2002; Carmichael and Bates, 2004). However, our observation of an increased pre-menopausal BC risk with augmented anthropometric factors and larger body size in early life contrasts with previous findings mainly in high-resource countries (Friedenreich, 2002; Carmichael and Bates, 2004).

Several biological mechanisms are hypothesised to explain how anthropometric factors influence BC risk. Obesity can increase levels of circulating endogenous sex hormones, insulin and insulin-like growth factors that all, in turn, increase risk (Vainio et al, 2002). The findings in post-menopausal women accord with 
Table 2 OR of BC for anthropometric factors

\begin{tabular}{|c|c|c|c|c|}
\hline \multirow[b]{2}{*}{ Factors } & \multicolumn{2}{|c|}{ Pre-menopausal } & \multicolumn{2}{|c|}{ Post-menopausal } \\
\hline & $\begin{array}{c}\text { Case/control } \\
(898 / 1182)\end{array}$ & OR $(95 \% \mathrm{Cl})$ & $\begin{array}{c}\text { Case/control } \\
(968 / 691)\end{array}$ & OR $(95 \% \mathrm{Cl})$ \\
\hline \multicolumn{5}{|c|}{ Height (in cm) } \\
\hline$<160$ & 734/99| & $1.00-$ & $829 / 634$ & $1.00-$ \\
\hline$\geqslant 160$ & |47/|82 & $1.05(0.81-1.38)$ & $103 / 48$ & $1.61(1.08-2.42)$ \\
\hline Unknown & $17 / 9$ & $1.39(0.41-4.76)$ & $36 / 9$ & $1.04(0.32-3.35)$ \\
\hline \multicolumn{5}{|c|}{ Height (in cm) (urban) ${ }^{\mathrm{b}}$} \\
\hline$<160$ & $251 / 294$ & $1.00-$ & $341 / 252$ & $1.00-$ \\
\hline$\geqslant 160$ & $52 / 54$ & $1.03(0.62-1.69)$ & $44 / 20$ & $1.89(0.97-3.67)$ \\
\hline Unknown & $13 / 7$ & $1.26(0.22-7.24)$ & $34 / 4$ & $1.45(0.33-6.36)$ \\
\hline \multicolumn{5}{|c|}{ Height (in cm) $\left(\right.$ rural) ${ }^{c}$} \\
\hline$<160$ & $483 / 697$ & $1.00-$ & $488 / 382$ & $1.00-$ \\
\hline$\geqslant 160$ & $95 / 128$ & $1.05(0.76-1.46)$ & $59 / 28$ & $1.52(0.90-2.57)$ \\
\hline Unknown & $4 / 2$ & $2.37(0.34-|6.6|)$ & $2 / 5$ & $0.41(0.03-4.94)$ \\
\hline \multicolumn{5}{|l|}{$B M l\left(k g / m^{2}\right)^{a}$} \\
\hline$<25$ & $560 / 845$ & $1.00-$ & $559 / 450$ & $1.00-$ \\
\hline $25-29.9$ & $256 / 268$ & $1.33(1.05-1.69)$ & $297 / 185$ & $1.29(1.00-1.66)$ \\
\hline$\geqslant 30$ & $65 / 60$ & $1.56(1.03-2.35)$ & $76 / 47$ & $1.00(0.64-1.54)$ \\
\hline Unknown & $17 / 9$ & $1.58(0.46-5.42)$ & $36 / 9$ & $1.07(0.33-3.45)$ \\
\hline \multicolumn{5}{|c|}{ BMI $\left(\mathrm{kg} / \mathrm{m}^{2}\right)$ (urban) $)^{\mathrm{b}}$} \\
\hline$<25$ & |75/207 & $1.00-$ & $192 / 158$ & $1.00-$ \\
\hline $25-29.9$ & $98 / 109$ & $0.99(0.65-1.5 \mid)$ & $142 / 86$ & $1.32(0.89-1.97)$ \\
\hline$\geqslant 30$ & $30 / 32$ & $1.19(0.64-2.24)$ & $51 / 28$ & $0.89(0.49-1.62)$ \\
\hline Unknown & $13 / 7$ & $1.30(0.26-7.56)$ & $34 / 4$ & $1.47(0.33-6.49)$ \\
\hline \multicolumn{5}{|c|}{ BMl $\left(\mathrm{kg} / \mathrm{m}^{2}\right)(\text { rural })^{\mathrm{c}}$} \\
\hline$<25$ & $385 / 638$ & 1.00 & $367 / 292$ & 1.00 \\
\hline $25-29.9$ & $158 / 159$ & $1.56(1.17-2.09)$ & $155 / 99$ & $1.30(0.92-1.83)$ \\
\hline$\geqslant 30$ & $35 / 28$ & $1.97(1.12-3.49)$ & $25 / 19$ & $1.15(0.58-2.28)$ \\
\hline Unknown & $4 / 2$ & & $2 / 5$ & $0.42(0.03-5.16)$ \\
\hline \multicolumn{5}{|c|}{ Waist size (in $\mathrm{cm})^{\mathrm{b}}$} \\
\hline$\leqslant 85$ & $631 / 918$ & $1.00-$ & $557 / 486$ & $1.00-$ \\
\hline$>85$ & $250 / 254$ & $1.24(0.96-1.62)$ & $380 / 199$ & $1.61(1.22-2.12)$ \\
\hline Unknown & $17 / 10$ & $1.19(0.37-3.90)$ & $31 / 6$ & $2.88(0.76-10.90)$ \\
\hline \multicolumn{5}{|c|}{ Waist size (in cm) (urban) ${ }^{b}$} \\
\hline$\leqslant 85$ & $208 / 235$ & $1.00-$ & $213 / 185$ & $1.00-$ \\
\hline$>85$ & $96 / 113$ & $0.97(0.61-1.54)$ & $178 / 89$ & $1.71(1.12-2.61)$ \\
\hline Unknown & $12 / 7$ & $1.25(0.20-7.83)$ & $28 / 2$ & $5.90(0.92-37.96)$ \\
\hline \multicolumn{5}{|c|}{ Waist size (in $\mathrm{cm}$ ) (rural) $^{c}$} \\
\hline$\leqslant 85$ & $423 / 683$ & $1.00-$ & $344 / 301$ & $1.00-$ \\
\hline$>85$ & $|54 /| 4 \mid$ & $1.43(1.03-1.99)$ & $202 / 110$ & $1.54(1.06-2.23)$ \\
\hline Unknown & $5 / 13$ & $1.34(0.25-7.17)$ & $3 / 4$ & $1.65(0.13-21.77)$ \\
\hline \multicolumn{5}{|c|}{ Hip size $(\text { in } \mathrm{cm})^{\mathrm{a}}$} \\
\hline$\leqslant 100$ & $723 / 1037$ & $1.00-$ & $673 / 584$ & $1.00-$ \\
\hline$>100$ & $157 / 135$ & $1.47(1.05-2.06)$ & $264 / 101$ & $2.42(1.72-3.4 I)$ \\
\hline Unknown & $18 / 10$ & $1.47(0.47-4.60)$ & $31 / 6$ & $3.46(0.89-13.35)$ \\
\hline \multicolumn{5}{|c|}{ Hip size (in cm) (urban) $^{b}$} \\
\hline$\leqslant 100$ & $230 / 278$ & $1.00-$ & $242 / 218$ & $1.00-$ \\
\hline$>100$ & $73 / 70$ & $1.49(0.89-2.51)$ & $149 / 56$ & $2.65(1.60-4.37)$ \\
\hline Unknown & 13/7 & $2.16(0.40-11.76)$ & $28 / 2$ & $6.85(1.04-45.06)$ \\
\hline \multicolumn{5}{|c|}{ Hip size (in $\mathrm{cm})\left(\right.$ rural) ${ }^{c}$} \\
\hline$\leqslant 100$ & 493/759 & $1.00-$ & $431 / 366$ & 1.00 \\
\hline$>100$ & $84 / 65$ & $1.48(0.94-2.34)$ & $115 / 45$ & $2.34(1.44-3.82)$ \\
\hline Unknown & $5 / 3$ & $1.34(0.25-7.16)$ & $3 / 4$ & $2.03(0.15-28.09)$ \\
\hline \multicolumn{5}{|l|}{$W H R^{\mathrm{a}}$} \\
\hline$\leqslant 0.85$ & $295 / 398$ & $1.00-$ & $261 / 159$ & $1.00-$ \\
\hline$>0.85$ & $585 / 774$ & $0.92(0.74-1.13)$ & $676 / 526$ & $0.74(0.57-0.97)$ \\
\hline Unknown & $18 / 10$ & $1.27(0.40-3.98)$ & $31 / 6$ & $1.95(0.51-7.48)$ \\
\hline
\end{tabular}


Table 2 (Continued)

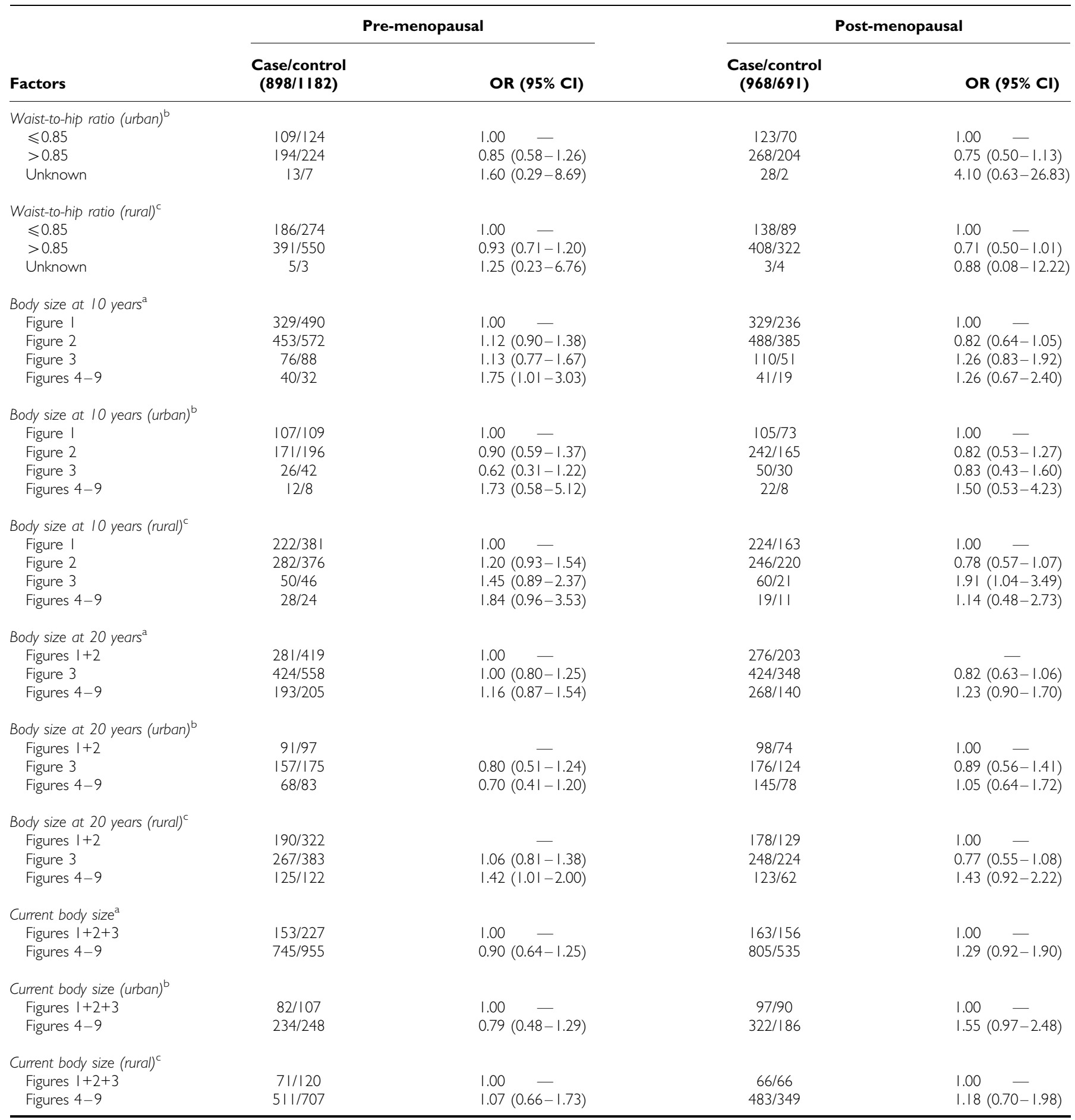

$\mathrm{BC}=$ breast cancer; $\mathrm{BMI}=$ body mass index; $\mathrm{Cl}=$ confidence interval; $\mathrm{OR}=$ odds ratio; $\mathrm{WHR}=$ waist-to-hip ratio. ${ }^{\mathrm{a}}$ Adjusted for age, centre, religion, marital status, education, socioeconomic status, residence status, parity, age at Ist childbirth and duration of breast feeding, physical activity and variables in the table (where appropriate). ${ }^{\circ}$ Only urban, adjusted for age, centre, religion, marital status, education, socioeconomic status, parity, age at Ist childbirth and duration of breast feeding, physical activity and variables in the table (where appropriate). 'Only rural, adjusted for age, centre, religion, marital status, education, socioeconomic status, parity, age at Ist childbirth and duration of breast feeding, physical activity and variables in the table (where appropriate).

previous studies mainly in high-resource countries (Vainio and Bianchini, 2002; Carmichael and Bates, 2004).

The lack of an association between increased WHR and BC risk is again inconsistent with previous evidence (Connolly et al, 2002; Harvie et al, 2003), perhaps reflecting measurement error and a different effect of fat distribution in India compared to that in high-resource countries. Weight gain during adulthood has been widely identified as a risk factor for post-menopausal BC (Trentham-Dietz et al, 2000; Han et al, 2006), being considered a 'probable' cause by the WCRF (1997). We found that increased 
Table 3 BC risk factors by place of residence

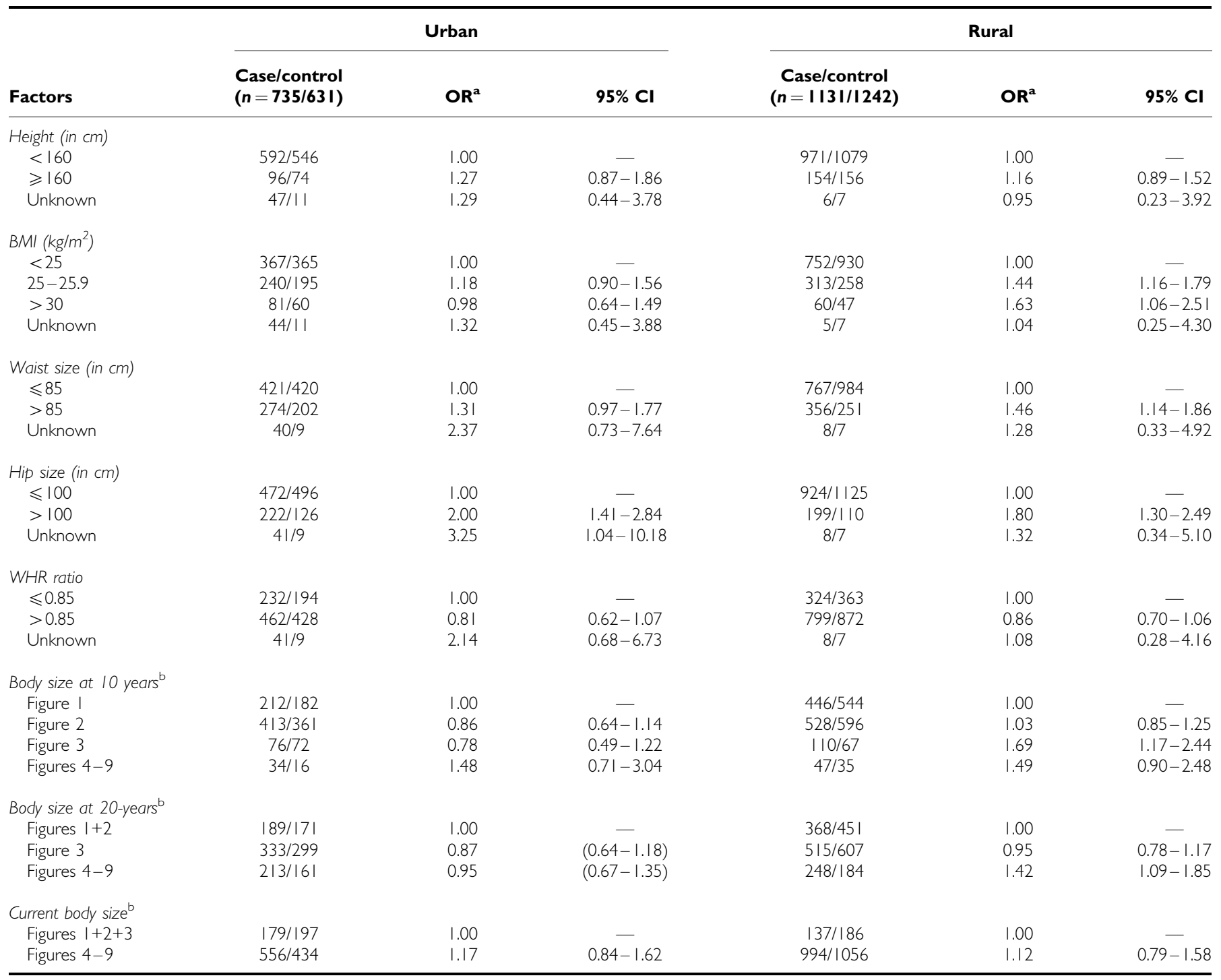

$\mathrm{BC}=$ breast cancer; $\mathrm{BMI}=$ body mass index; $\mathrm{Cl}=$ confidence interval; $\mathrm{OR}=$ odds ratio; WHR = waist-to-hip ratio. ${ }^{\mathrm{a}} \mathrm{OR}$ adjusted for age, centre, religion, marital status, education, socioeconomic status, parity, age at Ist childbirth, duration of breastfeeding, menopausal status, physical activity and variables in the table (where appropriate). ${ }^{\text {b Refer }}$ Figure I.

body size at early years of life and at the time of interview increased BC risk for both pre- and post-menopausal women.

As with any case-control study, case participants may have recalled certain exposures differently from controls, especially for exposures widely thought to be BC-associated. In fact, the relationship with body size was largely unknown to our subjects, thus this source of bias is unlikely. However, measurement error (non-differential misclassification), leading to the loss of power and underestimation of OR, is a plausible source of bias. Another potential bias is that control women (accompanying the cancer patients) were chosen because they were more mobile (and consequently less obese). However, the anthropometric factors were measured in most case women after their primary surgery, with some weight loss, and thus the $\mathrm{BC}$ risk might not be affected.

The 10-year arbitrarily chosen period for migration need not imply a change of lifestyle. The proportion of migrants from rural to urban areas was higher in both Trivandrum and (especially) Chennai than that from urban to rural areas. The urban-rural difference is minimal in Kerala and a typical rural lifestyle might be confined to Tamil Nadu. As low risk (rural) migrants were considered as urban, some urban-rural differences according to the various factors may have been reduced. However, the proportion of migrants from rural to urban areas and vice versa was similar among both cases and controls so that risk values might not be much affected.

Despite the limitations inherent in case-control studies, the advantages of the present study include a large size (it is the largest case-control study of BC in India), detailed assessment of anthropometric factors, large heterogeneity of exposures and more than $90 \%$ participation.

In summary, we observed that urban women were more obese and had relatively larger body size in the early years of life. A positive association was observed between $\mathrm{BC}$ risk and augmented anthropometric factors for both pre- and post-menopausal BC among rural and urban women. The study supports the hypotheses that increased anthropometric measures are important determinants of BC in India, although they do not appear to contribute appreciably to the urban-rural $\mathrm{BC}$ differences. 


\section{ACKNOWLEDGEMENTS}

This study was funded by the International Agency for Research on Cancer (IARC), WHO, Lyon, France. We thank the staff in

\section{REFERENCES}

Armitage P, Berry G (1994) Statistical Methods in Medical Research. Oxford: Blackwell Scientific Publication

Breslow NE, Day NE (1980) Statistical Methods in Cancer Research. Vol II. The Design and Analysis of Case-Control Studies. Lyon: IARC Scientific Publications No. 31

Carmichael AR, Bates T (2004) Obesity and breast cancer: a review of the literature. Breast 13: 85-92

Chadha SL, Gopinath N, Shekhawat S (1997) Urban-rural differences in the prevalence of coronary heart disease and its risk factors in Delhi. Bull World Health Organization 75: 31-38

Connolly BS, Barnett C, Vogt KN, Li T, Stone J, Boyd NF (2002) A meta analysis of published literature on waist-to-hip ratio and risk of breast cancer. Nutr Cancer 44: 27-38

Friedenreich CM (2002) Review of anthropometric factors and breast cancer risk. Eur J Cancer Prev 10: 15-32

Han D, Nie J, Bonner MR, McCann SE, Muti P, Trevisan M, RamirezMarrero FA, Vito D, Freudenheim JL (2006) Lifetime adult weight gain, central adiposity, and the risk of pre- and postmenopausal breast cancer in the Western New York exposures and breast cancer study. Int J Cancer 119: $2931-2937$

Harvie M, Hooper L, Howell AH (2003) Central obesity and breast cancer risk: a systematic review. Obes Rev 4: 157-173

Parkin DM, Whelan SL, Ferlay J, Teppo L, Thomas DB (2002) Cancer Incidence in Five Continents Vol VIII. Lyon: IARC Scientific Publication No. 155 the participating hospitals for their cooperation, all those providing data, Veronique Benhaim-Luzon, IARC, for database management and RK Prasanthkumar, RCC, for secretarial assistance.

NCRP, National Cancer Registry Programme of India (2006) Population Based Cancer Registry Report. New Delhi: Indian Council of Medical Research

Royal College of Physicians Report (1998) Clinical Management of Overweight and Obese Patients with Particular Reference to the Use of Drugs. London: Publications Unit Royal College of Physicians

Singh RB, Sharma JP, Rastogi V, Raghuvanshi RS, Moshiri M, Verma SP, Janus ED (1997) Prevalence of coronary artery disease and coronary risk factors in rural and urban populations of north India. Eur Heart J 18: $1728-1735$

Trentham-Dietz A, Newcomb PA, Egan KM, Titus-Ernstoff JA, Baron JA, Storer BE, Stampfer M, Willett WC (2000) Weight change and risk of postmenopausal breast cancer (United States). Cancer Causes Control 11: $533-542$

Vainio H, Bianchini F (eds) (2002) Weight Control and Physical Activity. IARC Handbooks of Cancer Prevention Vol 6, IARC Press: Lyon, France

Vainio H, Kaaks R, Bianchini F (2002) Weight control and physical activity in cancer prevention: international evaluation of the evidence. Eur J Cancer Prev S 2: $94-100$

WCRF (1997) Food, Nutrition and Health: A Global Perspective. Washington: World Cancer Research Fund/AICR

World Health Organization (1998) Obesity: Preventing and Managing the Global Epidemic. Report of a WHO consultation on obesity, Geneva 